\title{
Síntese genética
}

E.M. de M elo e Castro*

* Poeta, crítico, ensaísta, professor visitante da Área de Estudos Comparados de Literaturas de Língua Portuguesa da USP. 
- A crítica genética está fortemente ameaçada pelos meios informáticos de produção e tratamento de texto !

Várias vozes o dizem com saudosismo e apreensão ...uma ciência com tão poucos anos de afirmação ...tão excelentes resultados ...tão promissoras expectativas ...um prazer de pesquisa ... de reconstituição processual ...de coleccionismo ...finalmente uma mudança nos estudos críticos ...não já o estudo dos textos finais e fixos, mas o texto no processo de fazer-se ...talvez a resposta a essa decantada inquietação de saber como se faz um poema ou um romance ...talvez até porque se faz e porque se fez este poema ou este romance...

Maravilhas estas que a nova barbárie informática ameaça com o desaparecimento dos manuscritos, das rasuras, das emendas, das notas à margem em letra miudinha quase indecifrável, mas que provavelmente continham uma nova achega, uma sugestão, uma revelação!

Agora, informaticamente os textos fazem-se e refazem-se, compõem-se, descompõem-se e recompõem-se, misturam-se, emendam-se, perdem-se e recuperam-se, aumentam ou diminuem de extensão, a pontuação modifica-se, os parágrafos reorganizam-se, os discursos direto e indireto rearticulam-se, os versos encontram a medida certa ou a rigorosa distribuição espacial, a palavra exata, a expressão precisa, o adjetivo justo, a intencionalidade desejada... sem que de tudo isto e de muito mais reste um sinal, uma pista de pesquisa, uma sombra sequer.

Isto porque ao usar um computador para escrever, o escritor adquire meios de alteração do seu texto, rápidos e eficazes, mas que não deixam traços indiciais 
do processo de composição, a não ser que o autor os registe (salve) a par e passo, o que geralmente não é prático e perturba a execução da escrita.

Para nós, os novos bárbaros informáticos equipados ciberneticamente, o processo da escrita sofre uma profunda alteração, mesmo mental, pois se por um lado possuímos meios rapidíssimos de emenda e alteração, pelo outro a própria velocidade do sistema acelera a elaboração mental do texto, exigindo do escritor um maior rigor conceptual, podendo até levá-lo a novas construções sintáticas e escriturais. Creio que o uso inovador e transgressivo da pontuação da sequência metonímica dos discursos direto e indireto, criados por J osé Saramago em muitos dos seus romances é, além de outras possíveis interpretações, o fruto de um fenómeno dessa natureza.

Ao abandonarmos a escrita à mão deixamos também as emendas nas entrelinhas, as chamadas à margem, no cimo ou no pé da página, as rasuras de vocábulos na busca mais ou menos desesperada do termo, da referência ou da expressão mais adequadas, etc.,etc.; já não fazemos a segunda versão à mão ou à máquina, nem a terceira, nem a quarta... mas apenas corrigimos, alteramos, modificamos, aprimoramos o texto diretamente digitado no computador e "salvo" numa "disquete" de trabalho. O texto final, esse é que será conservado na memória do computador e registado numa disquete de back-up como segurança e para futuros usos. Ao destinatário será também enviada uma "disquete" e, como deferência, uma cópia feita na impressora periférica do computador.

Ao que parece acabou o manuscrito com todas as suas delícias estéticas, psicológicas e de crítica genética... Mas será realmente assim ? - Poderemos assim tão facilmente abdicar do prazer e da conveniência próprios da escrita manual? - Creio que não. A experiência que hoje já possuímos sobre a evolução dos suportes e dos meios de comunicação indica-nos que um novo suporte ou um novo meio nunca anula totalmente os que historicamente os precederam. $\mathrm{O}$ conhecimento da fabricação do papel na E uropa durante o século XI e o invento dos caracteres móveis para a imprensa no século XV que operaram uma revolução na difusão dos textos, não acabaram com a caligrafia, mas, sim, enfatizaram-na como arte ao mesmo tempo conceptual e visual. Também os meios de escrita manual evoluíram e se sofisticaram, desde o uso das penas de pato, com a invenção do lápis, do aparo de aço, da caneta de tinta permanente, da esferográfica e da máquina de escrever. Hoje podemos e continuaremos a escrever sobre papel usando todos esses meios conforme o nosso gosto e conveniência.

O que os meios informáticos nos trazem de novo é a substituição dos átomos do papel e da tinta pelos bits ou unidades desmateriais da informação virtual, sem que isso implique a radical abolição do uso desses materiais pesados. 
De fato o que nós temos na tela do computador são pixels, ou seja, unidades de representação visual provenientes de emissões de raios catódicos que ao atravessarem essa tela se transformam em fotões. E ssas emissões de raios catódicos são controladas no interior do computador, através dos ships, constituindo os bits como unidades de informação num sistema digital binário. Citando Nicholas Negroponte ${ }^{1}$ :

Um bit não tem cor, tamanho ou peso e pode viajar com a velocidade da luz. É o menor elemento atómico na cadeia AND da informação. É um modo de ser: ligado ou desligado, verdadeiro ou falso, em cima ou em baixo, dentro ou fora, preto ou branco. Por razões práticas consideramos que ele é 1 ou 0 . 0 significado do 1 ou do 0 é uma outra questão."

De um sistema pesado necessitando de papel, instrumento escrevente, tinta, uma mão e um cérebro humanos, escrever é agora um processo quase desmaterilizado, isto é, realizado através de impulsos elétricos, restando como elementos pesados, constituídos de átomos de matéria, os elementos humanos: a mão e o cérebro. M as uma mão e um cérebro mortos não poderão escrever... A atividade cerebral que comanda a mão é por sua vez também marcadamente desmaterial na sua componente elétrica, não se podendo omitir a mente (espiritualidade ?) investida na criação do pensamento e da escrita.

Por isso a desmaterialização da escrita está, contrariamente ao que superficialmente se julga, a aproximar mais e mais esse ato, dito de fixação e comunicação do pensamento, das suas origens na atividade cerebral e espiritual do homem, revelando de um modo cada vez mais evidente a relação indissociável entre a escrita e a elaboração do próprio pensamento, fato esse que todo o escritor e pensador há muito conhecem. É que pensar e escrever são funções genésicas desde há muitos milhares de séculos, indissociáveis do próprio homem. Sendo a fixação e a comunicação do pensamento escrito apenas fases posteriores.

M as escrever, como ato de pensamento que é, não depende exclusivamente dos meios usados para se realizar e se os meios informáticos são interessantes na aceleração e estimulação do processo, eles não constituem uma opção única. A escolha dos meios de escrita faz parte da liberdade que está embutida no próprio ato de pensar-escrever. Escrever à mão é um exercício somático de prazer e dor que muitas vezes se revela na estrutura e no sentido da própria escrita e disso não desejaremos jamais abdicar, segundo creio. Por outro lado a escrita à mão pode assumir o papel de uma liberdade fragmentar na tomada de notas e apontamen- 
tos súbitos para serem mais tarde submetidos a escrutínio e tratamento informático.

Mas não devemos esquecer que usar um computador para escrever através do teclado e do "rato" (mouse) é também um exercício de elevada coordenação psicomotora capaz, por isso, de proporcionar os seus próprios prazeres e dores...

Evidenciando o aspeto de síntese que o ato de pensar-escrever comporta, como processo de criação, (mesmo no caso de um pensamento semanticamente analítico), a utilização de meios informáticos tem em si própria a possibilidade de transformação dos textos escritos. Essa possibilidade de transformação é assim uma característica estrutural desses mesmos textos. Por isso pode dizer-se que o texto produzido informaticamente é em si próprio anamórfico. Desaparece assim a ideia de texto fixo ou final, fato este que curiosa e contraditoriamente vai ao encontro da noção básica da crítica genética :

Este novo enfoque implica, se não uma escolha, pelo menos algumas preferências : da produção sobre o produto, da escritura sobre o escrito, da textualização sobre o texto, do múltiplo sobre o único, do possivel sobre o acabado, do virtual sobre o 'ne varietur', do dinâmico sobre o estático, da operação sobre a obra, da génese sobre a estrutura, da enunciação sobre o enunciado, a força da inscrição sobre a forma do impresso."

Assim define Almuth G résillon o espírito da crítica genética ${ }^{2}$.

Nesta perspectiva de crítica genética, a ênfase das preferências é inequivocamente colocada do lado do processo fluido e dinâmico da produção dos textos, pensando nessas características como ante-textuais, e conduzindo ao aparecimento de um texto final imutável.

Ora é essa imutabilidade do texto que os meios informáticos põem em causa, não se podendo mais considerar nenhum texto como final, já que todos os textos são transformáveis e que de um texto se podem sempre gerar outros textos.

Partindo desta constatação fatual do texto sintético, isto é, sintetizado no computador, a leitura da citação feita acima, sem necessidade de nada alterar, enumera as preferências de uma síntese genética, no espaço do pós-textual, ou seja, de uma operação de produção de novos textos, por anamorfose, a partir de um texto tido como originário, num processo provavelmente sem fim e que só o computador possibilita.

É certo que todo escritor pode sempre alterar os seus textos através da reescrita na busca da perfeição como era o caso, por exemplo, de Carlos de Oliveira que, a cada re-edição dos seus romances e poemas, os modificava e alterava pro-

2 “Elements de Critique Généti que”. Paris: PUF, 1994. 
fundamente. Mas não é dessas alterações que agora falamos, mas sim daquelas que só o uso do computador possibilita e que constituem uma ordem diferente na própria noção de texto.

As transformações anamórficas dos textos são, assim, tornadas possíveis num triângulo de interatividade entre o operador, o computador e o programa e é dessa sinergia que resulta uma nova capacidade criativa e talvez mesmo uma nova poética a que se poderá chamar de infopoética.

A característica primeira da infopoética é precisamente a transformabilidade e a não existencia de texto final ou definitivo, fato que deriva da natureza virtual dos textos ou objetos gerados no computador e cuja razão de transformação está contida nos programas usados. No entanto o processo é sempre conduzido pelo autor na sua qualidade dupla de operador e de crítico, a par e passo, dos resultados obtidos. Só ele de fato os pode aceitar, corrigir ou rejeitar, já que uma relativa imprevisibilidade dos resultados é outra característica infopoética e só após a realização das operações de transformação poderemos julgar o novo texto(assim obtido) quanto ao seu valor poético e estético.

Mas não se trata de operações casuais do tipo das propostas e praticadas pelos dadaístas, mas sim de anamorfoses originadas pelas deslocações dos pixels no espaço da tela do computador segundo algoritmos estabelecidos pelo programa, a que geralmente se chama 'filtros' e que pod em evidentemente ser ou não ser randômicos. O estudo desses algoritmos e desses filtros é o objeto de uma nova poética a que se pode chamar de 'poética do pixel' e cujo desenvolvimento não caberia no escopo deste artigo.

O que se deseja ressaltar é, como noutro passo da obra citada diz Almuth Gresillon, “... um estado instável de tensões entre um saber transmitido e um desejo de invenção, estabilizado entre esse novo equilíbrio de formas e de forças que é o texto acabado." M as , se isso é assim para a análise genética, para a síntese genética de que aqui falamos, todo o processo começa na desestabilização do texto acabado, que assim deixa de o poder ser. 0 igual tratamento de signos verbais e não verbais apela para novas concepções de escrever e de ler. O equilíbrio de formas e de forças, supostamente alcançado, transforma-se num desequilíbrio projetivo que vai ao encontro de novos significados para os quais talvez ainda não dispomos de codificações interpretativas e nas quais o referido desejo de invenção se manifesta , mas nunca como um fim ...

É como se análise genética e síntese genética fizessem parte de um vasto processo de ascensão do texto, numa espiral criativa, em que tudo pudesse ser escrito e visto numa luz mais complexa, mas por isso mesmo talvez mais profundamente nossa ... 
E is como uma aparente ameaça pode ser transformada na abertura de novos e insuspeitados territórios para a invenção e para a criatividade.

E ste processo, aqui chamado de síntese genética, pode ser acompanhado na sequência de poemas que completa este artigo. Parte-se de um poema escrito segundo uma estética que pratiquei na década de 60 , caracterizada pelo verso curto e por imagens fortemente visuais e espaciais, numa articulação sintática fragmentar. Este poema poderia ser considerado como um texto final, mas agora o processo de criação reinicia-se: primeiro realiza-se uma espacialização malarmeana de que o computador fará várias versões muito rapidamente; seguemse sucessivas sobreposições do mesmo texto que aumentam a complexidade tanto textual como de leitura ; o processo continua com uma anamorfose circular a que se junta um sinal de pontuação para enriquecer semanticamente o poema; iniciam-se então novas anamorfoses que levarão ao desaparecimento dos signos létricos e à esferização tridimensinal, atingindo-se assim um novo nível de complexidade que apela para uma leitura predominantemente visual-icônica. O processo de síntese genética poderia continuar com outras transformações mas eu, como autor, aqui, provisoriamente, o interrompo.

Poderia o leitor continuar este processo se, em vez de um texto fixado no papel, eu Ihe pudesse oferecer uma disquete de computador, usando um programa como o Adobe Photoshop. Partilharíamos assim a autoria dos novos textos eventualmente conseguidos. 


\section{Drente}

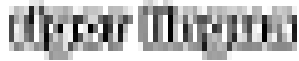

monptos minulion

dils anifo do row

"พpक

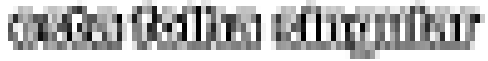

mo Iftmm the ar

"Mos w wal wWwh

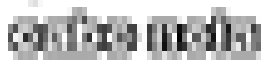

po hor armos

wa thoctu

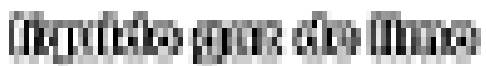

wats burboto

the lowms

whon the lin

FMin

hobsos phiw

coprowimin whothe 
Fracta

rigor

língua complexa

diz

expressa máquina

mais

do que

\section{ESTA}

folha singular

na finura do AR

que o azul espesso

MAR

cabe nela e o

rugosso se

faz

líquido GAZ

de limo

verde território

do BRANCO

céu de luz sem núvens

esfera plana

visões

expandindo 


\section{Fracta}

\section{Fracta}

rigor

língua complexa

diz

língua complexa

máquina

diz ESTA

que expessa

ESTA

que o azul espesso

do $A R$

líquido $G A Z^{\circ}$ al espesso

MAR

\section{verde território}

rugosso se faz

líquido GAZ máquina

rigor

mais

do que expessa

mais

do

folha singular

na finura do $A R$

folha singular

cabe nela

e na fíura MAR

rugosso se faz cấlimga e 


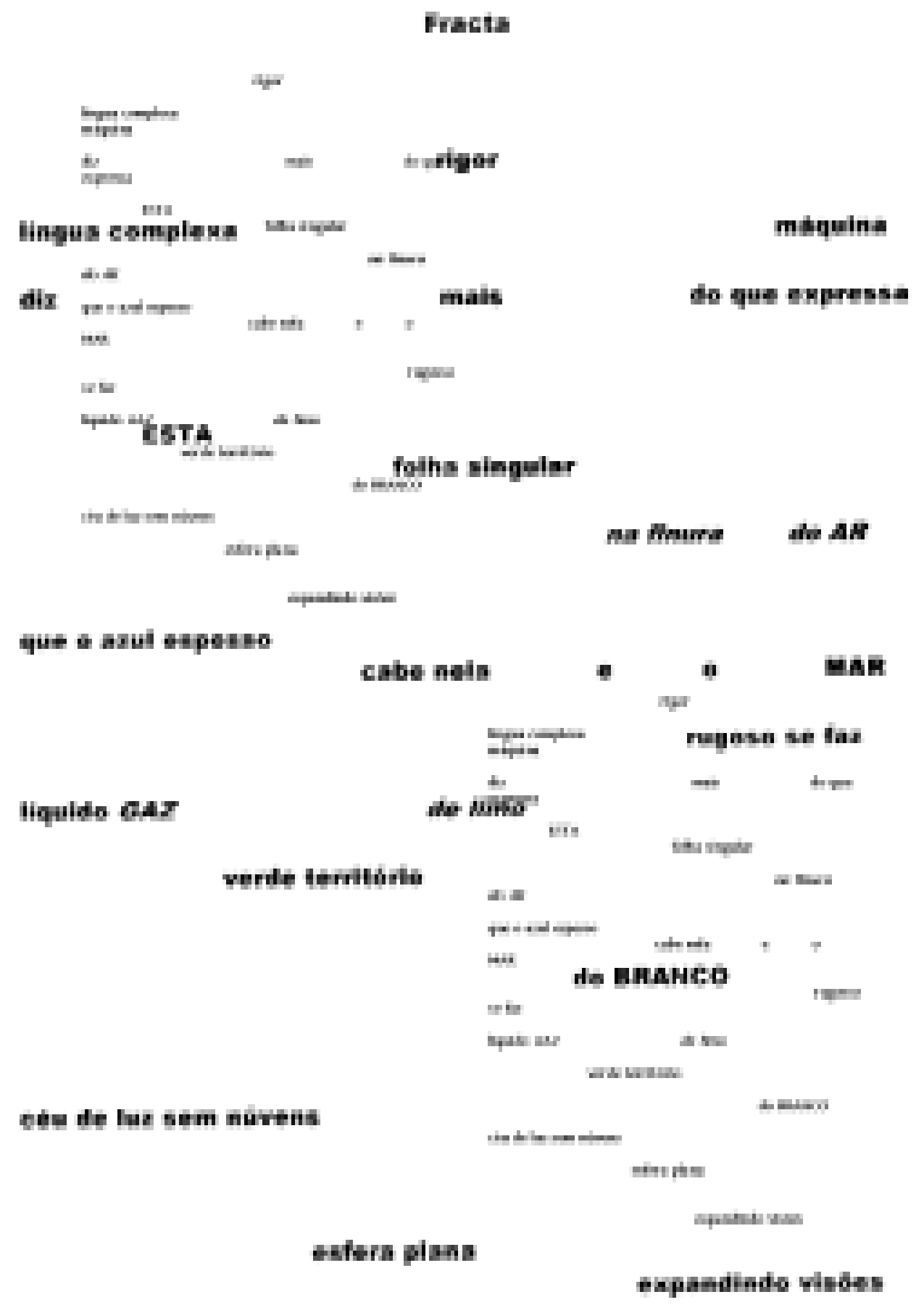




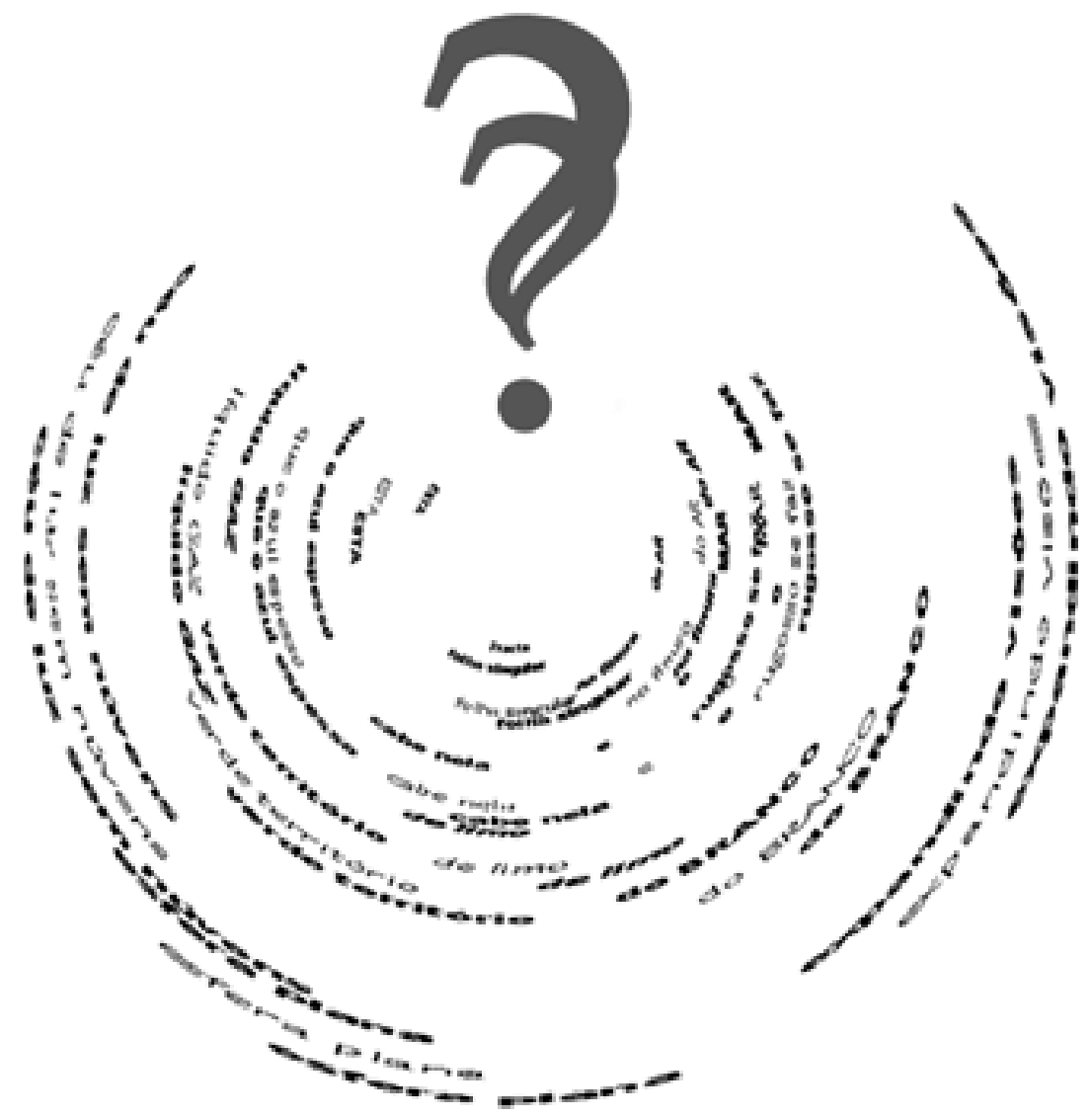




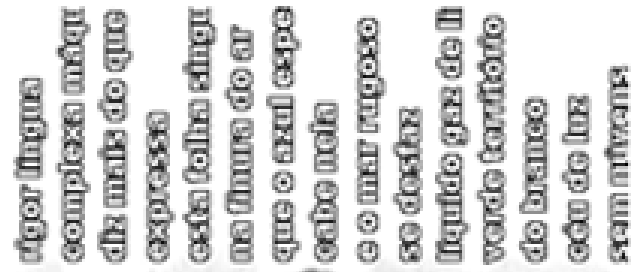
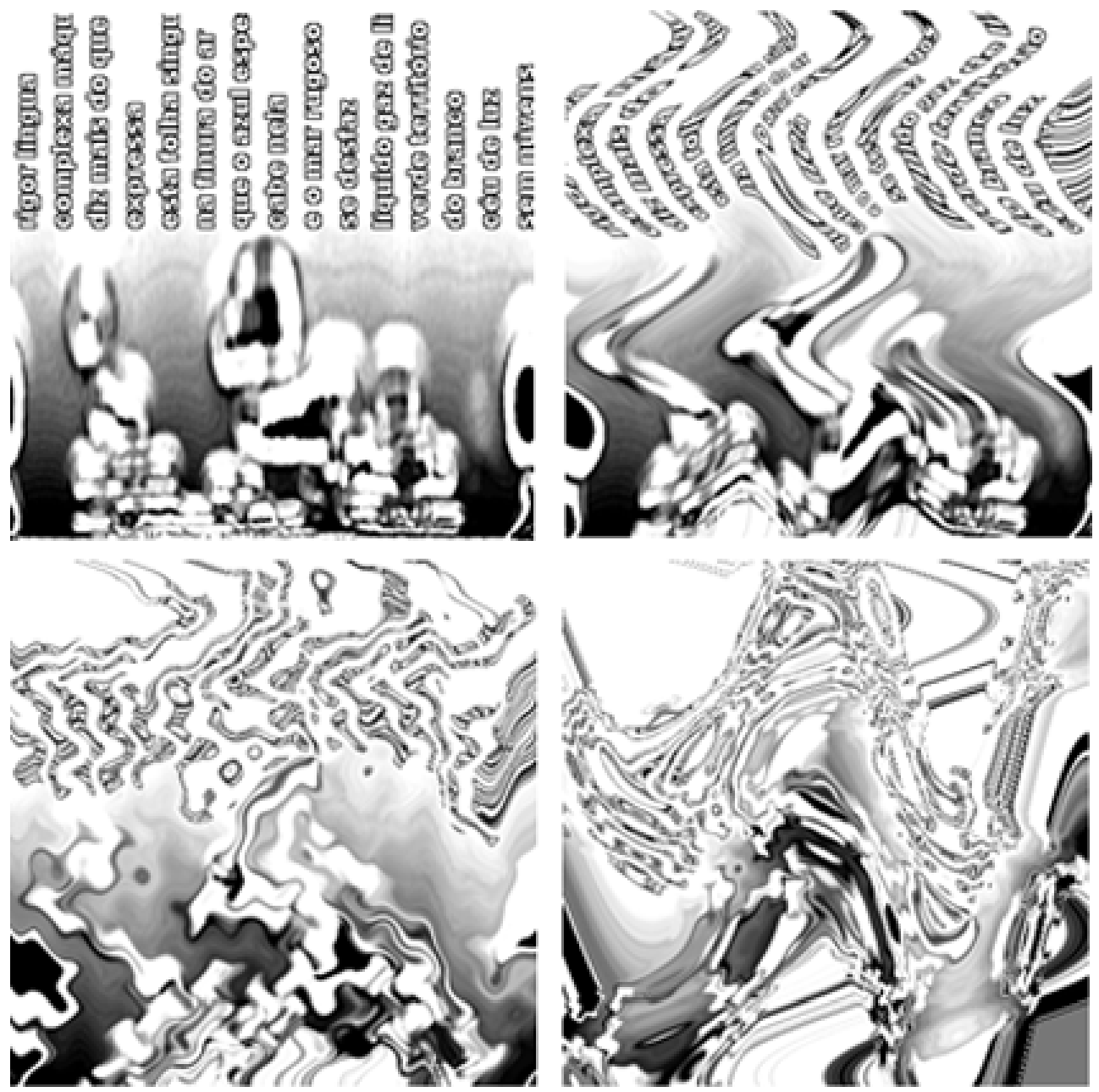


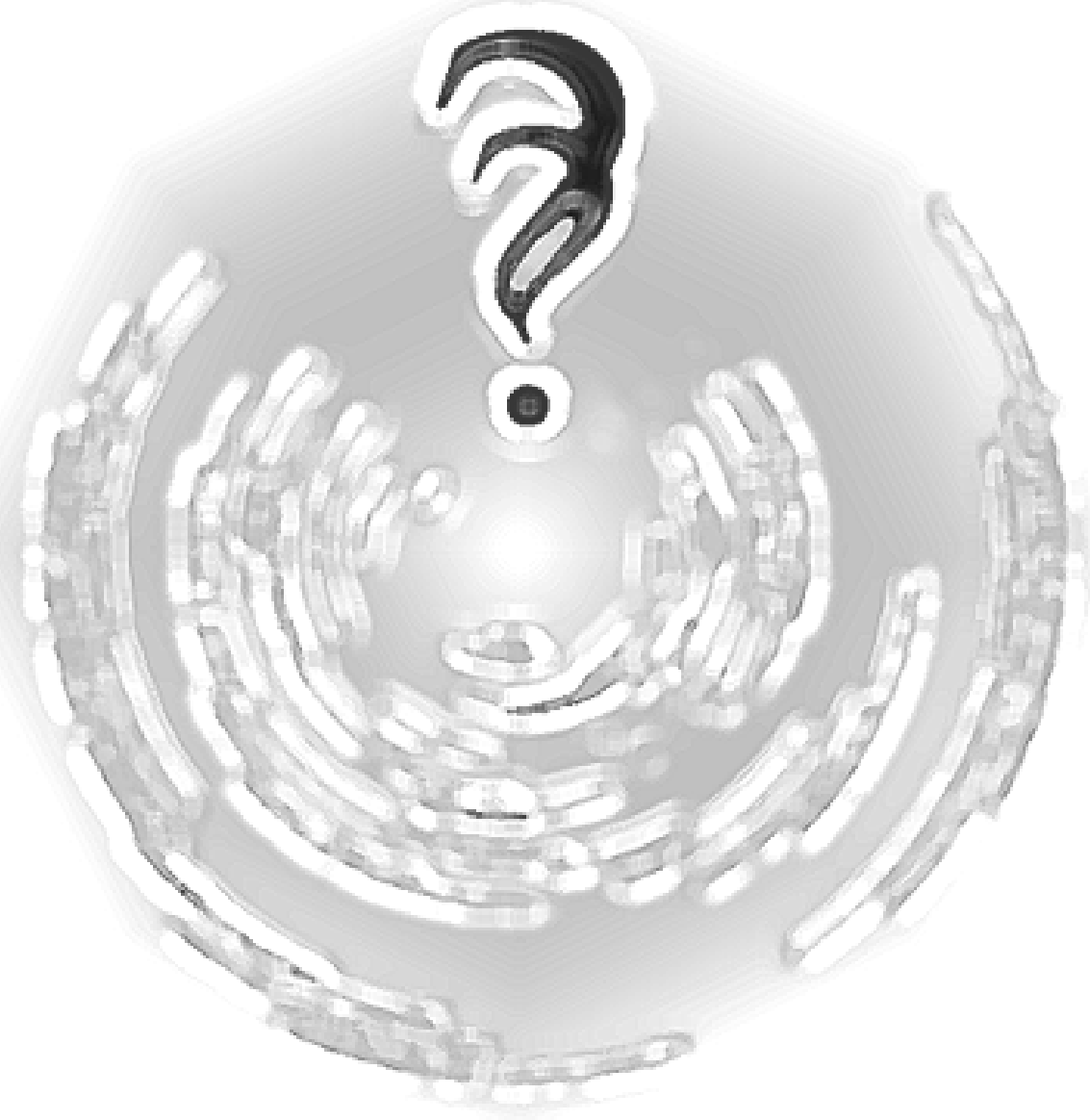

